\title{
DIVERSITY, SOCIAL INQUIRIES, AND EPISTEMIC VIRTUES
}

Jonathan E. Adler*

SÍNTESE - A teoria das virtudes epistêmicas (VE) sustenta que as virtudes dos agentes, tais como a imparcialidade ou a permeabilidade intelectual, ao invés de crenças específicas, devem estar no centro da avaliação epistêmica, e que os indivíduos que possuem essas virtudes estão mais bem-posicionados epistemicamente do que se não as tivessem, ou, pior ainda, do que se tivessem os vícios correspondentes: o preconceito, o dogmatismo, ou a impermeabilidade intelectual. Eu argumento que a teoria VE padece de um grave defeito, porque fracassa ao se ajustar à natureza social dos questionamentos (epistêmicos) típicos. Esse e outros defeitos relacionados a esse infectam o paralelo que os teóricos VE traçam entre virtudes epistêmicas e morais. Ao prometer o incremento na proporção de crenças verdadeiras sobre crenças falsas, ou ignorância as virtudes epistêmicas não podem desempenhar um papel paralelo àquele que Aristóteles reserva às virtudes morais ao prometer o incremento em nossa felicidade e no bem-estar da comunidade. A minha rota para essas críticas é feita das razões sobre por que os agentes (sociais) devem buscar a obtenção de seus objetivos morais e epistêmicos diferentemente nos papéis que atribuem às virtudes.

PALAVRAS-CHAVES - Virtude epistêmica. Divisão de trabalho epistêmico. Diversidade. Conhecimento. Falibilidade. Virtude moral.
ABSTRACT - Epistemic Virtue (EV) theory holds that virtues of agents, like impartiality or openmindedness, rather than specific beliefs, should be at the center of epistemological evaluation, and that individuals with those virtues are better positioned epistemically than if they lacked them or, worse, if they instead had the corresponding vices: prejudice, dogmatism, or close-mindedness. I argue that EV theory suffers from a serious flaw because it fails to accommodate to the social nature of typical (epistemic) inquiries. This and related flaws infect the parallel that EV theorists allege between epistemic and moral virtues. In promising to improve our ratio of true beliefs to either false beliefs or ignorance, the epistemic virtues cannot play a roll parallel to that which Aristotle claims for the moral virtues in promising to increase our happiness and the well-being of the community. The path to these criticisms I introduce by offering reasons for why (social) agents should seek to realize their epistemic and moral goals very differently in the respective roles they accord to the virtues.

KEY WORDS - Epistemic virtue. Division of epistemic labor. Diversity. Knowledge. Fallibility. Moral virtue.

* Department of Philosophy - City University of New York - Brooklyn College and the Graduate School.

For helpful comments when this paper was in its infancy, I thank John Greco.

\begin{tabular}{|l|l|l|l|l|l|}
\hline VERITAS & Porto Alegre & v. 50 & n. 4 & Dezembro 2005 & p. 37-52 \\
\hline
\end{tabular}


1. The underlying theme of this paper is that the usual ideals for character traits and methodological guides to further truth acquisition (and falsity reduction) must be modified within social, as contrasted to individual, inquiries. My explicit theme is an application of this underlying one to Epistemic Virtue (EV) Theory. EV theory holds that the development in an individual of virtues like impartiality or open-mindedness, as contrasted to bias, dogmatism, or close-mindedness, will render that individual in a better epistemic position than if he lacked them.

The critical implication of the explicit theme is that EV theory suffers from a serious flaw because it fails to accommodate to the social nature of many (epistemic) inquiries. The flaw infects the parallel that EV theorists draw between epistemic and moral virtues. I deny that the epistemic virtues benefit us to realizing a better ratio of true over false beliefs (or ignorance) in parallel to how the Aristotelian moral virtues are expected to increase one's happiness (and that of the community). Specifically, I deny the implication that the more virtue, all other things equal (e.g. tragedies aside), is the better.

2. Epistemic virtue theorists aim to reorient epistemology as moral virtue theorists aim to reorient moral philosophy. The project, according to one statement, is the

epistemological analogue of the claim made by recent ethicists that the moral virtues should be the focus of ethics $[\ldots]$

Epistemology is to be reoriented so that

the intellectual virtues being the, or a primary, focus of epistemological inquiry (Kvanvig, 1992: p. vii).

The epistemic virtues aim at truth or knowledge and they are designed, or to be inculcated, so as to realize these aims. The locus of epistemic evaluation is to be shifted from a belief to the believer, as moral virtue theory seeks to shift the locus of evaluation from acts to agents. Most EV theorists, though not all, are ambitious in taking the epistemic virtues, properly understood, to explicate core epistemic notions - justification, warrant, and knowledge, even if these notions are reinterpreted in their accounts. ${ }^{2}$

However, beyond these claims, there is a divide among EV theorists. ${ }^{3}$ One approach, which is closest to reliabilism, takes the locus of evaluation to be cognitive faculties, including largely automatic ones, like memory or perception. The other approach, which aligns itself with moral virtue theory, takes the locus of evaluation to be intellectual virtues as character traits. (Still, even this dividing line is murky - most of those who take the latter approach adopt reliability con-

2 For an exception, see Montmarquet (1987, 1993). Zagzebski (2001: 248) notes that since EV theories "identify a property of the knower as the value-conferring property of epistemic states" they are not committed to "the view that justification, warrant, and knowledge have propositional objects".

3 See Greco 2000. Such an approach allows a central place for cognitive values like speed and power. See also Goldman (1986: Chapter 6), and, within EV theory, Kvanvig (1992: p. 118). 
straints.) Thus, Zagzebski argues at length for a close modeling of the intellectual (epistemic) virtues on Aristotle's account of the moral virtues, including that to act virtuously is to act for the sake of that virtue - to be virtuously motivated. In the Introduction to her book she writes:

[...] I will argue that the relationship between the evaluation of cognitive activity and the evaluation of acts in the overt sense usually reserved to ethics is more than an analogous one. I will argue that the intellectual virtues are so similar to the moral virtues in Aristotle's sense of the latter that they ought not to be treated as two different kinds of virtue. Intellectual virtues are, in fact, forms of moral virtue [...]

Finally, I will argue that intellectual virtue is the primary normative component of both justified belief and knowledge. The justifiedness of beliefs is related to intellectual virtue as the rightness of acts is related to moral virtue in a pure virtue ethics (1996, xiv-Xv).

3. My main criticisms are directed to this second approach, so that when I speak of "EV theory" that is the view to which I will be referring. I use "inquiry" in a very broad and loose way to refer to any fairly systematic method to obtain, modify, and improve beliefs toward realizing their aim of truth or knowledge by way of investigating specific claims or hypotheses through empirical or critical methods. I focus on social inquiries in settings other than institutional ones, like science. I am particularly concerned to challenge EV theories in application to the broadest domain of non-institutional inquiries, as with a town committee set up to determine the feasibility of expanding an existing school to handle growth in the student population. Nevertheless, a number of examples are from institutional inquiries both for their familiarity and because if the problems for EV theories arise in those settings, they will clearly be more formidable in non-institutional ones.

As a way to address epistemological issues, the alleged parallel between the moral and epistemic virtues seems extremely implausible on its face. I'll set out four differences that show a wide gulf between the tasks and the domains of the moral and epistemic virtues, which the criticisms below of EV theory draw upon. The differences are: first, differences in the activities or domains to which the virtues are to serve as guides; second, differences in the import of their respective first-person points of view; third, differences in the relation of these respective virtues to self-interest; and fourth, differences in the roles of these respective virtues in realizing their ultimate end or objective.

First, the epistemic virtues are primarily directed to guiding one's intellectual activities (reasonings, thoughts, inferences, or beliefs), while the moral virtues are largely directed to how we treat others. The moral virtues characteristically operate as restraints on actions to regulate and harmonize our (social) behavior toward others. We act honestly; we examine our position with intellectual honesty.

There is then much more latitude for deviation from norms in the epistemic than in the moral realm. The costs of error or the value of being correct are far greater in the moral than in the epistemic realm. When we act immorally we typically hurt others. But in the epistemic realm the harm (to others) is usually weak 
and indirect. Consequently, even under the restrictions noted above, we can - and we should be and we are - more carefree ("Popperian") in the range of our epistemic acts than in our ethical acts, and that is essential to advancing inquiry. (I do not deny that epistemic judgments - or, theoretical reasoning as issuing in belief can be enormously consequential. But the influences of our epistemic judgment on how we act is a further step from that judgment, a species of practical reasoning. I also do not want to quibble with anyone who maintains that epistemic judgments, such as what lines of inquiry to pursue, count as action. The wide difference in risks, dangers, or costs between the domains remain. If I ignore certain evidence that I should obtain, I am epistemically negligent or irresponsible. But the evidence itself couldn't care less. If I ignore you at a dinner party, I am rude and I offend, and so harm, you.)

Second, the first-person perspective of an inquirer acting contrary to an epistemic virtue is, as noted earlier, to deny that he holds it dogmatically or in violation of some epistemic virtue (e.g, to believe hastily). But for unethical acts, the parallel fails - there is no conceptual compulsion to judge one's immoral act moral. I can believe that I acted rudely and that it is wrong, whereas I cannot continue to believe that $\mathbf{p}$, and to believe that I believe it dogmatically.

Third, the ethical virtues serve to curb or thwart self-interest, while the epistemic virtues serve mainly to guide it. To act justly and honestly, when these virtues are called upon (e.g. the cashier returns too much change to you and you think that no one else notices it) is to forgo clear benefits or rewards for oneself. ${ }^{4}$ I do not doubt that ultimately, in the long run, and from a broader perspective (of garnering the cooperation of others), the moral virtues do further self-interest in the community, whose betterment filters through to individual members. But the benefits are neither direct nor assured, and they call for regular sacrifice of immediate self-interest.

However, in areas of interest, our self-interest lies in correct beliefs, rather than incorrect ones or ignorance, since these provide the best assurance that our actions succeed. The epistemic virtues are good guides to acquiring true beliefs, as by keeping oneself responsive to the evidence. So we generally have a built-in, clear motive toward acting in accord with the epistemic virtues that we do not have for the moral virtues.

Fourth, realizing the truth-aim of the epistemic virtues is filled with surprise. The surprise holds even for ordinary inquiries, since at its minimal it simply amounts to our ignorance, in advance, of their outcomes. But the community composed of the morally virtuous is thereby constituted by happiness-features under normal functioning. Kindness or honesty are traits in others that we normally admire. We know that they add to our security, pleasure, and well-being. No combination of epistemic virtues constitutes discerning a (new) truth. The search

4 I ignore long-run solutions to repeated Prisoner's Dilemmas that attempt to show how morality can be developed out of self-interest. 
for truth is a mystery. We do not grasp in advance the truth as a way to shape how we should act epistemically virtuously. However, it is evident to us how our happiness is furthered by the moral virtues and that is why we seek to instill them widely.

The shortest path to the criticisms of EV theory below opens with this last difference: The epistemic virtues and vices can serve a strategic purpose that is unnecessary for the moral virtues. Directed as epistemic virtues are mainly to intellectual matters (the first difference above), there is little potential harm done in deviance. We need to think strategically because the goal of the epistemic virtues and inquiry is to discern new truths and to expose false beliefs, which are, from our point of view as inquirers, a mystery. So we want to guard against eliminating viable contenders, which involves guarding against our own potential misjudgments. We also want to reduce our burden by exploiting the potential contribution of others in shared inquiries, even when ideological foes.

But in the case of happiness there is little mystery. The difficulty is rather to curb individual self-interest that is the barrier to cooperation from which we all benefit. However, there is only a need to guide, not to restrain, self-interest in the epistemic domain, since self-interest seeks satisfaction in knowing more about what matters to one.

This last disparity hints that the criticisms of EV theory below have an "invisible hand' form. The discovery of new truths best emerges from granting a free hand to self-interest, given a pluralist community with a high degree of involvement in inquiry. Although this is only a facet of the criticism, it still might be thought to seriously backfire. Could not an argument, akin to our central one, be mounted to the conclusion that the flourishing of a community, particularly its economic advancement, under conditions of modest need and scarcity, requires various moral vices like greed, along lines of Adam Smith's 'invisible hand'? Perhaps, for example, the virtue of beneficence allows, or even requires, that the virtuous agent here and there performs acts of greed or flattery, and, in part, because these are also aspects of our nature as social beings.

However forceful this suggestion is for bringing the moral and epistemic virtues closer, it does not upset my criticisms. For the model of the moral virtues that EV theorists draw their parallel to is Aristotle's, and he could not hold such a mixed - invisible hand - view of the ways that the virtues benefit.

We proceed to develop into specific criticisms of EV theory the wide gulf just enumerated between the moral and the epistemic virtues.

4. The primary criticism of EV theories will be that both directly and indirectly, by way of their parallel with the moral virtues, they are committed to a uniformity of epistemic virtues across an inquiry as best, while our argument concludes that non-uniformity, above a high threshold of epistemic virtues, is best. In brief, it is epistemically better in an inquiry for most to be epistemically virtuous rather than all. That criticism divides into three. 
The first is that the great value to inquiry of dissent is better realized if the epistemic virtues are not held uniformly across the community, as EV theories recommend. Inquiries function well only if there is lively diversity of ideas or opinions on the major issues, which follows from Mill's (1978) defense of free speech and the dangers of a lack of dissent to deliberative decision making.

The second, which is engaged with the first, is about the individual inquirer. It claims that a freer reign for non-virtuous motives than a demand for purity is also expected to be comparatively better. Consequently, I can agree with a lot of what epistemic virtue theorists want to say in praise of specific epistemic virtues and with much of what they say about the advantages of these virtues for the inquiring community. Nevertheless, these two criticisms, which lend detail to the abstract presentation of the four differences set out above, sever the alleged parallel between the epistemic and moral virtues. Specifically, I deny that those who proceed well epistemically require epistemically virtuous motives. To the contrary, the demand for such purity of motives will retard inquiry.

Third, much of the obvious losses or dangers of deviation from the epistemic virtues and of their impurification are promised to be effortlessly compensated for through the on-going operation of the division of epistemic labor. The division enormously lightens the informational burdens of inquiry, which is essential, given our limited time and resources (Kitcher 1993, Chapter 8). Those who are better positioned to gather relevant data or to perform tests or to critically examine certain claims should do so, and share their findings with other members. In deciding what informational sources to attend to for increasing your understanding on virtually any topic, you rely on the direct recommendations of others or through the citations found in various respected writings. However fallible and subject to fads is this unavoidable short-cut, you would either be overwhelmed to try to determine what is worthwhile on your own or else you would be arbitrary, picking virtually haphazardly from among the vast amount published or reported. The division of epistemic labor will help to protect dissent and to promote inquiry, while avoiding the heavy demands of purity on inquirers to which EV theory is committed.

If a community is made up of the epistemically virtuous, they will each be open-minded and highly responsive to the weight of evidence and argument. However diverse the set of ideas (hypotheses, etc.) in play initially, there will be times when one idea seems to be better to a plurality of members of the community than others, even if only marginally. The threat to diversity arises because this marginal preference and slight advantage will amplify for social and personal reasons, such as the greater enjoyment of harmony, and for epistemic reasons, especially of reasons to defer to the community's judgment. Inquirers give some positive weight to the consensus or dominant view of others, greater weight with greater consensus, assuming a virtuous respect for the community's workings. Even those starting off with contrary ideas will be moved by the (apparent) weight of evidence and argument, as well as their virtuous intellectual respect for one another and the community, toward favoring the leading ideas and disfavoring the competing ones. Under realistic conditions, the slight advantage will often grow to 
a commanding dominance, depleting diversity in the forums of public discussion, rendering it very difficult to give a hearing to ideas that conflict with the dominant view and criticisms of it.

By contrast, a community where a substantial, but still very few, members are dogmatically committed to their disfavored positions will, under similar circumstances, not be moved to fall in line with the dominant view. If they can remain actively involved in the discourse, rather than dismissed as cranks or contrarians, they will help keep their deviant ideas in play. One of these may come to be seen as better than the fairly dominant one and, in any case, as Mill stressed, the controversy will disallow dominant ideas from merely being taken for granted. It will have to keep up the intellectual fight. I assume that this community is epistemically in better shape than the previous one.

Why dogmatic, rather than just reasonable dissenters? The question misconstrues the argument: Even if the dissent is dogmatic, it is advantageous.

The stipulation is realistic, since the dissenters deny the force of argument or evidence which all take to favor the dominant view. To this extent, the dogmatists have epistemically virtuous grounds to view themselves as dogmatic, which is in conflict with their first-person view of themselves. To be realistic, my stipulation assumes only first, that the intellectual community is basically well functioning; second, that a person's belief as dogmatically held is susceptible to objective determination, dependent primarily on the level of available evidence; third, that dogmatism comes in degrees, and that the dissenters we are imagining are not at the extreme (pig-headed). I do not however assume that dogmatism is a consistent trait of character, rather than restricted to certain inquiries. (See further note 7.)

The key observation is that the increasing consensus of the community on an idea is a strong reason for each to endorse it. Those who have the intellectual virtues of modesty and honesty are more likely than those lacking these virtues to allow their contrary judgments to be overruled by the community consensus. The issue at hand is not one where a dissenter can readily explain away the group consensus on the basis of illicit grounds such as forceful, perceived self-interest, as with refusals of a town to allow for low-income housing based predominantly on an expected drop in their property values.

An everyday example that brings out both the value and the difficulty of dissent is of a local parent-school organization, where the parents are setting up a fur fashion show to raise funds for various worthy school projects. You are opposed to the wearing of fur. I think it is easy to imagine that your grounds are not decisive and yet the consensus of your neighbors, whom you cannot dismiss as narrow-minded or elitist is overwhelming. If you dig in your heels, arguing strongly against the proposal, it is easy to envisage that you appear to them as extremist and dogmatic, and for good reasons. In order to enter your dissent, you will have to overcome your own (virtuous) pulls toward accepting the dominant view. You will likely frustrate your personal virtues of good spirit and interest in being well liked and enjoying group solidarity. To sustain your position personally, you will find it difficult not to become defensively dismissive and intolerant of their view, a further move away from virtue and purity. 
Nevertheless, as with the 'emperor's new clothes', your willingness to speak out, despite the prospect of ostracism, may be the only way to keep valuable critical opposition in play. The very act of dissent stands a good chance of encouraging others to speak out as well, though they are so far silent, although actually unenthused too about the dominant view. The main point, in short, is that your dogmatic dissent may advance the epistemic interests of the community compared to one of consensus which, I claim, will partly be due to a uniformity of epistemic virtues like open-mindedness, and intellectual honesty and modesty.

5. Psychologists and social scientists teach us of the danger of 'groupthink' (Janis 1972) that is one source for my concerns about promoting an ideal of a uniformity in open-mindedness, which I treat (for brevity) as including to follow where the evidence or argument leads and to defer - give weight - to dominant opinions in one's intellectual community. Groupthink is the tendency of groups to come to a shared decision not because it is best or optimal, but because the group dynamics favors agreement and strongly disfavors dissent. If there is a dominant view in the group and an absence of dissent, empirical studies show that the outcome of exchanges within the group will be to polarize positions further than how they were originally held by individual members - a crucial step toward extremism.

Those who have studied the dangers of groupthink have also told us how remarkably little it takes to break its grip: It turns out that in many groupthink settings, if only one respected individual - lacking, for example, a reputation as a contrarian - does voice dissent, that is usually sufficient to break the groupthink grip. This vulnerability is a presupposition of my previous and next example, and it supports my claim that the alternative to EV theory that I defend requires no more than a small minority to lack the epistemic virtues.

As I return to below, think of how worthwhile it is for livening up a discussion and for breaking a smug solidarity for one to play 'devil's advocate.' Think also, however, of the personal and social strains against so doing in ordinary circumstances, where that role is not overtly assigned. If you are genuinely playing, so that you do not hold the belief that you defend to the group, the pretense is difficult to sustain. Worse, if the role-playing continues for an extended period, others in the group are unlikely to think that you are merely playing.

For an example, imagine an extremist, say a Strom Thurmond-type, in the U.S. Senate. I will use the name 'Strom Thurmond' to suggest the character I mean to represent, though the illustration is fanciful. Assume that a Democratic and Republican committee of the Senate formulates a bill on defense appropriations that achieves unanimous support. So it's likely to receive quick passage. However, the bill is complex. Because of the usual time constraints, pressures, and political interests, little attention would be paid to many of its details. But the

For discussion and references see Sunstein 2003. 
members know that one of Thurmond's favorite tactics for destroying a bill is to expose and exaggerate minor weaknesses or errors, in order to smear the whole document. In this situation, Thurmond's extremism will probably serve the interest of truth (in this case, an optimal or excellent defense appropriations bill). It will compel those who write and check the document to closely scrutinize the details.

The description of Thurmond's actions is meant to satisfy some epistemic vices (e.g. prejudiced, dogmatic), however these are properly characterized. I am not staking my own position that his maneuver is a smear tactic because, e.g., it focuses on minor failings. Similarly, the unreasonableness of Thurmond's extremism is not an inference from locating his position at the end-point of a range of views on an issue.

If Thurmond's viceful actions and tactics play a vital positive role in the inquiry on the Senate bill and if in many, typical inquiries there is no regularly available and feasible substitute for this role, the lesson is that a non-uniform distribution of the epistemic virtues, and even the exhibiting of vice-like behavior (e.g. dogmatism), is necessary to advance epistemic inquiries against the regular threat of homogenity of ideas.

The lesson holds though only if the Thurmond-case is not a rarified construction. The example needs to display epistemic difficulties that inquiries are expected to confront commonly. The realistic nature of the illustration, however, depends upon three restrictions, already suggested: First, Thurmond, though a detested voice, still must be heard respectfully (by other Senators and the public). Second, Thurmond works his (usefully) devious ways through admissible activities--public argument and standard political arm-twisting, not through illicit or illegal surreptitious means e.g., extortion. He grates on the system without seriously marring its functioning. Third, Thurmond remains in a small minority. Otherwise, were his extremism to spread, it would infect and sully the Senate's deliberative and decision-making processes.

6. The Thurmond example, like others below, is within an institutional setting, for reasons already noted. Aside from the codified (and enforced) nature of the rules of behavior and of individual advance in institutions, science, as the paradigm, they are equipped with powerful resources to sustain diversity and to motivate participation in inquiry: first, and crucially, there is strong incentive for originality, and so for divergence from standard positions and criticism of dominant views; second, the institution can impose a system or structure to generate diversity such as appointing - preferably, anonymously - a devil's advocate or those of unrepresentative background or ideology; third, there is rigorous checking (verification) of claims as a matter of course; fourth, one's professional and institutional life is different from one's social and personal life, though, by happenstance they frequently overlap. Thurmond's constituency is pleased by his grating on the workings of the Senate, and they reward him, through re-election, as well as adulation. 
As a consequence of this last disparity, the desire to be well liked and to be sociable, as a result of how one pursues (social-epistemic) inquiries, is much more of a problem in non-institutional settings. Socrates is famously disliked for his interrogation of citizens about matters of fundamental values. When groupthink takes place it is not so recognized - the agreement is taken as a convergence, not a reflection of the desire for group harmony. Even when some suspect otherwise, it is part of the groupthink not to acknowledge it. So dissenters are perceived as just not seeing the truth, and they stand a good chance of social alienation and ostracism.

7. Common sense reflection on time and motivation show that noncompliance with ideals like open-mindedness could be requisite for motivation to pursue inquiry and to success in it. ${ }^{6}$ Those with important or bold visions and theses could not pursue them, or not with intense single-mindedness, without wearing blinders to many objections that are taken seriously by others. As an obvious example, consider B.F. Skinner and others with grand projects, who are single-minded in their intellectual pursuit and correlatively have little time or patience to address the numerous criticisms of their positions. To address these objections, even if they could answer them, would distract them. As a result, their pursuit would be badly hampered, intellectual life the poorer.

Given the division of epistemic labor and the incentives of the academic world, however, there is little danger that their disinterest in the criticisms of their position will prevent those criticisms from pursuit, so long as their views retain prominence. One facet of the problem of uniformity raised is just that these incentives - publication and professional advance - are lacking, or much weaker and unsystematic, in non-institutional settings.

Another epistemic virtue that raises the incentive and uniformity problem is impartiality or fairness, particularly as applied to how one searches for evidence. A procedure that appears in conflict with this virtue is to stop searching when you have found supportive data, but not to, however, for unsupportive data. Robyn Dawes considers something like this overtly biased stopping rule irrational:

We double-check results that are displeasing to us, but we are much less apt to double or triple-check results that we find pleasing. (Dawes, 2000: 153)

Actually, I expect that the stopping rule is applied much more selectively than Dawes indicates, though I will not pursue this point beyond the observation that one line we draw follows on the first difference noted in the opening in relation to costs. When it comes to purchasing an expensive item, like a car, where a variety of independent sources can be easily examined (Consumer Reports, web sites), the stopping rule is much less favored than in opinionated or controversial topics, where one has mainly an intellectual stake.

In these next paragraphs, I draw from Adler 2004. 
In domains where the stopping rule operates for an individual, I grant that there is something right about Dawes suspicions, stemming from the values of impartiality and open-mindedness. Nevertheless, his dismissal of any such asymmetrical treatment of favorable and unfavorable sources is misguided. It stems from failure to give the costs of searching its due. It also ignores the role of the division of epistemic labor in lessening those costs to the individual, while encouraging others to articulate negative evidence more efficiently, since more in line with their expertise, time, and interests.

Opposition to the stopping rule also neglects the social commitments needed to keep intellectual inquiries going. These inquiries require loyalty in order to secure participation of others. I am not going to devote myself to an inquiry which requires the cooperation of others, if I know that their commitment will lapse whenever individual judgment casts doubt on the position (hypotheses) we hold. If the impartiality demanded is to view one's own position with the same detached, unbiased view as with which one views others, and to act accordingly, these commitments to a cooperative enterprise cannot be sustained. In his famous autobiography, revealing the seamier side of scientific pursuit, James Watson (1969) recounts how he and Francie Crick, on their way to discovering the double-helix structure of DNA, fed a rival bad information to keep him off track. Although this may be an extreme, it certainly is consistent with a realistic view of competition for, and cooperation toward, original discovery as at variance with a demand for purity of motive and action.

Dawes' suspicions are curious since, if I am correct, it is rife with counterexamples that he should appreciate, as it almost certainly characterizes his own practice. He neglects the first-person point of view of the inquirer, as if we would explain ourselves as acting on the stopping rule, when, in fact, conforming to it. But the pleasure from corroborative sources and the displeasure at dissenting ones are not how I represent to myself why I should double-check in one case, but not the other. In one case, there is conflict with my beliefs (arguments), so I have reason to double check, since doubting its reliability. But in the other case, there is accord with my beliefs, so I have much less reason to keep searching.

These conclusions appear too strong - justifying dismissiveness or prejudicial argumentation - even if it is granted that intellectual slack can be distributed across the division of epistemic labor and even if we put aside the cases where self-interest relaxes the stopping rule, if it will involve little effort. We are capable of (and must take) not only a first-person perspective from within our arguments, but also an observer or second-order one. From that point of view, one knows that some of one's beliefs, or the arguments for them, are likely distorted or mistaken, and one wants to know which. An excellent way to discern if one's beliefs or arguments are mistaken is to take seriously the objections of others or to examine potentially contrary sources. The inquirer, recognizing himself as fallible, has reason to examine some of these objections, even though he regards them as erroneous. (Adler, 2002: Chapter 11) 
In limiting the demands for virtue, as a condition of membership in an intellectual community or in the pursuit of inquiry, an obstacle is removed to inquirers articulating and defending their positions in public forums. The intellectual life of the community is benefitted. You all know highly original and productive thinkers whose motivation to contribute partly depends on the free reign of their intellectual immodesty (conceit, bragging), ruthlessness or indifference toward critics, coddling of loyal followers, vanity, and self-promotion (e.g., selfcitations). 'Vaulting ambition' is a spur to intellectual boldness, even if it is not an epistemic virtue or if it generally facilitates acquisition of non-virtuous traits of character. ${ }^{7}$

So long as the intellectual community's standards are high, I am arguing, tolerance for deviation from the epistemic virtues does better to maintain a lively variety of ideas in inquiry than would a demand for purity of motive. The former ease the burden on participation and even encourage it, since allowing inquirers to indulge their more self-interested and self-advancing motives. My criticisms of a demand for uniformity of virtues across the community is at one with my objection to a conception of the intellectual virtues as the high ideals that EV theorists propose, especially in regard to its demands for virtuous motivation within social inquiries.

8. The line of criticism that I have offered undermines the parallel with the Aristotelian moral virtues not only for the advocacy of a uniformity of virtue and motivational purity, but for its correlative recommendation that to discern how one should act one should follow those with the virtues and practical wisdom. In the example of Thurmond, he is doing what some person concerned with the epistemic advance of the community would do, or would encourage others to do, who recognized the danger of the consensus in the Senate. The result poses a further problem for Zagzebski who defines "justified" on analogy to "praiseworthy":

A person $\mathbf{A}$ is praiseworthy (justified) for doing an act (having a belief) $\mathbf{S}$ just in case $\mathbf{A}$ does what a virtuous person would (probably) do (believes what a virtuous person would [probably] believe) in the same circumstances and is motivated by virtuous motives. $(236)^{8}$

\footnotetext{
The prospects for EV theory drops precipitously if we abandon the Aristotelian portrait of character traits. The portrait requires that epistemically virtuous persons be consistent across settings in his guidance by the virtues, which I have accepted for the sake of discussion. The consistency requirement for the moral virtues, where it is far more plausible on grounds stated above, has been recently disputed on empirical grounds. See Doris 2002.

8 The definition follows Aristotle in distinguishing between the one who has the virtuous disposition and the neophyte who lacks the disposition, but attempts to conform to it (as a way, presumably, of developing the disposition and, ultimately, the character trait.) In the central argument, the distinction corresponds to that between the weaker thesis of prescribing actions in accord with the vice and the stronger thesis, dependent on our psychology, that to act in accord with the vice leads to the corresponding disposition or character trait.
} 
In the Thurmond example, his viceful acts promote epistemic ends, and better than if he had acted virtuously. But they require that he maintain his badly unjustified belief (that the bill is seriously flawed and should just be rejected). Yet, this is what an epistemically concerned individual would be pulled to do in those circumstances, albeit from a different motive. The dilemma is that either this is what an epistemically virtuous person would do or not. If it is not, then epistemic virtue and advance at the group level, and then derivatively for the individual, do not march in step. If it is, then the epistemically virtuous person acts for the goal (motive) of the epistemic virtues by bringing himself (or others) to engage in nonvirtuous acts.

Now it may seem that Zagzebski has a maneuver available to handle examples like this one. She claims that even if the vices are truth-conducive at a time, they will not be in the long run (and conversely for the virtues):

as long as we look at a large number of Joe's beliefs formed over time, openmindedness will be ultimately truth conducive, even for him. I conclude that it is true that an agent does not possess an intellectual virtue unless the trait as possessed by him is truth conducive in the long run, but there may be a period of time during which it is not truth conducive. (186)

But these claims do not resolve the difficulty, since they do not allow that deviation from the virtues and even acting on the vices can be regularly truth - or knowledge-conducive. In particular, they assist in off-setting tendencies both toward the homogeneity of ideas in the public forum and against strong participation in inquiry. The latter requires one to put forth and defend one's position, as well as to be willing to challenge dominant and admired voices.

9. In closing, I'll summarize and slightly extend my criticisms of EV theory as part of a response to what I take to be the main objection to them: Uniformity of epistemic virtues is not only compatible with a great diversity of ideas and methods, but it will encourage and promote it, including the motivation to pursue inquiry and the willingness to dissent, and far better than communities that fall short in the distribution of the epistemic virtues. It is bad pun to assimilate the "uniformity" of a uniformity of virtues to the "uniformity" of a uniformity of ideas. After all, originality and intellectual boldness, for obvious cases, are epistemic virtues. The demand for diversity and epistemically valuable motivation can be handled naturally by our self-interest, individual differences in our dispositions and

\footnotetext{
Further:

dogmatism is not truth conducive for most people most of the time. When intellectual vices are truth conducive, they are only truth conducive relative to a narrow range of belief-forming practices, usually of a single individual and usually only within the scope of a particular area of knowledge or belief...It is possible, of course, that a person is dogmatic only within a very limited area, one that he knows extremely well and one in which dogmatism is truth conducive. And it may even be possible that such a person has no tendency to dogmatism in areas in which it is not truth conducive. If this can happen, I am willing to say that this trait is not a vice. (1996: 193-194; she admits exceptions 312-19).
} 
background, the enjoyment of lively discussion, and the very large numbers involved in social inquiries in open, pluralist communities. ${ }^{10}$

If my criticisms are even roughly on target, the objection is unrealistic psychologically, socially, and epistemically. The objector and I agree that diversity of ideas is important for the well-functioning of intellectual inquiries, which is major source of epistemic advance. Communities of inquiry are vulnerable, however, to premature consensus with its correlative loss of diversity. The social problem is that communities of inquiry are still communities with an enjoyment of solidarity and consensus. These pleasures and rewards filter down to the individual level in social and psychological pressure toward harmony with others. Just as dissent among real inquirers is rarely purely intellectual, so intellectual engagement is rarely purely intellectual, even within academic settings and certainly not outside them. Differences over political and social issues, even when fairly abstract, inevitably give rise to personal differences and animosity toward those in opposition and to positive fellow feeling toward those who share one's views. There is also the epistemic pulls toward consensus: respect and deference to the community. Consequently, a small consensus favoring an idea, in areas where decisive evidence is difficult to come by, feeds on itself both socially and epistemically.

Outside of institutional settings, there is a lack of external motivation to pursue argument and to be original, specifically, to challenge a dominant view and to advance new ideas despite unpopularity. Of course, I allow for a good deal of intellectual curiosity, personality differences, especially in how outspoken one is and how much one needs to be popular, as well as great variation in individual orientation on sensitive issues e.g., a highly religious vs. a purely secular upbringing.

10 A word on the ground rules that have structured my argument that I provide in response to a helpful comment from the editor. I assume that the question of the proper motives and character for inquirers to best realize epistemic goals is to be answered without abstracting away from a range of normal human motives, interests, limits, and circumstances, particularly those that are central to pursuing inquiry: curiosity, competitiveness, a desire to understand, a need to economize, fallibility, dependence on others. There are, of course, epistemological issues or claims that warrant much greater idealization or abstraction. Thus, one might take the view that $p$ is proper for an agent to believe only if $p$ is what a rational being would believe for whom $p$ answered a question of his, when he had all the information that the agent does, and the rational being is reasoning correctly and his only aim is truth. Especially the last two of these idealizations are too strong for the problems that EV theory is meant to address, as well as for the extended comparison with Aristotelian moral virtues. Virtues are necessary to restrain and guide self-interest, and to overcome fallacious assumptions and inclinations (to e.g., dogmatism, partiality, and laziness) that are obstacles to improving knowledge. We cannot then maintain the problematic to which EV theory is addressed, while abstracting away from ourselves as rational creatures who have multiple interests and motives, who are fallible, limited, and dependent on information from others, with a complex psychology, and who can take advantage of our social participation in a community toward mutually beneficial ends. However, while I then do not idealize away from these conditions and circumstances, the realistic assumptions about our epistemic predicament that frame this paper are not restrictive or parochial. Assumptions of competitiveness or potentially corrupting motives or desires for popularity or group harmony are, I think, minimal assumptions about human social nature. In not abstracting away from them, no substantial limits are imposed on the epistemic inquiries to which our argument applies. In sum, the realism assumptions adopted here aim to fit comfortably between the extreme idealization that would nullify the problematic and the extreme ultrarealism or contextualism, which constricts the scope of the problematic that applies to most any systematic epistemic or cognitive inquiry. 
But these are far weaker, as our shared experience shows, than the personal, social, and epistemic pulls away from dissent and boldness in view of our fallibility and the serious possibility of false persuasion and groupthink. My conclusion is that given these realistic facts of non-institutional inquiries, which lack external incentives and procedures for enforcement, a community made up of the epistemically virtuous will be less able to resist cheap consensus and to motivate participation in inquiry and argumentation, than one that is made up of only mostly epistemically virtuous members. Further, even among those who are epistemically virtuous, they should not be saddled with the burden that their epistemic virtues parallel the Aristotelian moral virtues (as "means" between opposed extremes). The pleasure to be found with mature development of the latter, in a community of the like-minded, does not transfer to the epistemic virtues. Dissent requires a few who are intellectually obstinate and dogmatic to challenge the dominant view. Even those who are epistemically virtuous should not allow their self-interest to wait upon the arrival of virtuous motivation.

I take EV theory to imply the contrary, given their guiding parallel with the moral virtues, which the four differences I note at the opening argues is implausible. EV theory implies that an inquiring community with all, or just about all, who are epistemically virtuous is preferable to any that fall short of it (accidents aside), where epistemically virtuous acts require virtuous motivation. When the objection talks about dissent as thriving naturally on human diversity, self-interest, and the large number of members of the community of inquirers, I take it to tacitly concede the bulk of my criticism-what they are admitting is only that the absence of a uniformity of epistemic virtues probably will occur naturally (and thankfully).

Even here though the objectors do not appreciate that the obvious epistemic costs of some who lack the epistemic virtues or who even adopt some of the vices in inquiry can be compensated for effortlessly by the division of epistemic labor, which itself arises naturally (from our diversity of interests and limits on opportunity). There is little parallel with the moral domain at the crucial juncture of the first difference stated in the opening. The epistemic virtues are directed to judgments of little consequence, while moral ones are directed to actions of personal and social consequence. Take again the moral and epistemic virtue of impartiality. I have defended an easing of impartiality as a demand. In particular, I allow greater freedom in how an individual treats objections and counter-evidence to one's position than under an impartialist demand. On an impartialist demand, one seeks an objective assessment of various sources of relevant information. One then follows that assessment rather than one's own inclination as to which sources are preferable, even though the preferable, and more pleasurable, sources are those that are antecedently known to favor one's view. Not only is engaging in inquiry better motivated by the lessened demand, but it is implausible that the commitment to intellectual inquiry (pursuing a certain position) can be sustained, unless others know that you share that commitment. You cannot share that commitment, yet admit to treating your position with the same detached impartiality as others would, who are not members of your group. 
Of course, there are limits to this partiality and there must be given that the ultimate aim remains truth. There is little danger here that this partiality will harm that aim, so long as there are competing groups pursing rival positions. I may ignore a source that provides strong evidence against my position, but the rival groups will surely find and publicize it. The division of epistemic labor is at work. But I will also not regularly ignore such sources since my self-interest lies with getting matters correctly, which, as is obvious, lies with responsivity to the evidence and to the weight of argument.

There is also little danger of harm from this partiality since it is directed to judgment, not action. The moral domain is quite different. If I discriminate in favor of a stranger for a neighbor's son in hiring, there is obviously no division of moral labor that can compensate for it, even granted the possibility of moral experts.

The concern with virtuous character itself is a recognition that our intellectual judgment is a small part of the influences on how we act, which is typically affected by a host of motives of which we have limited access. It is one thing to decide that I should hire fairly, it is another for this intellectual judgment to really penetrate to how I act in conflict situations (e.g., one candidate is a friend's son). Character goes far deeper to withstand various motivational influences on actions. But in the intellectual domain what inquiry wrestles with are only those reasons that can be publicly presented and evaluated, not their efficacy at the level of action nor the myriad of psychological or non-conscious influences on them.

\section{References}

Adler, J. E. (2002). Belief's Own Ethics (Cambridge: The MIT Press). (2004). "Shedding Dialectical Tiers: A Social-Epistemic View" Argumentation 18: 279-293.

Doris, J. (2002). Lack of Character: Personality and Moral Behavior (Cambridge: Cambridge University Press). Goldman, A. I. (1986). Epistemology and Cognition (Cambridge: Harvard University Press).

Greco, J. (2000). Putting the Skeptic in his Place (Cambridge: Cambridge University Press).

Janis, I. (1972). Victims of Groupthink (Boston: Houghton Mifflin).

Kitcher, P. (1993). The Advancement of Science (Oxford: Oxford University Press).

Kvanvig, J. L. (1992). The Intellectual Virtues and the Life of the Mind (Lanham, Maryland: Rowman \& Littlefield Publishers, inc.)

Mill, J. S. (1978). On Liberty E. Rapaport, ed. (Indianapolis: Hackett).

Montmarquet, J. (1987). "Epistemic Virtue" Mind 96: 482-497.

(1993). Epistemic Virtue and Doxastic Responsibility (Lanham, Maryland: Rowman and Littlefield).

Sunstein C. R. (2003). Why Societies Need Dissent (Cambridge: Harvard University Press).

Watson, J. D. (1969). The Double Helix (New York: Mentor).

Zagzebski, L. (1996). Virtues of the Mind (Cambridge: Cambridge University Press).

. (2001). "Recovering Understanding" in Knowledge, Truth, and Duty Matthias Steup, ed.

(Oxford: Oxford University Press): 235-251. 